08

\title{
Микротвердость и показатель преломления двухкомпонентных покрытий на основе диоксида титана
}

\author{
(C) А.Б. Аткарская, ${ }^{1}$ В.В. Дьяченко, ${ }^{2}$ В.М. Нарцев, ${ }^{1}$ В.Г. Шеманин ${ }^{2}$ \\ ${ }^{1}$ Белгородский государственный технологический университет им. В.Г. Шухова, \\ 308012 Белгород, Россия \\ ${ }^{2}$ Новороссийский политехнический институт Кубанского государственного технологического университета, \\ 353000 Новороссийск, Россия \\ e-mail: atkarsk06@mail.ru
}

(Поступило в Редакцию 6 апреля 2016 г.)

Изучены стеклянные композиты с двухкомпонентными оксидными золь-гель покрытиями системы $\mathrm{TiO}_{2}-m \mathrm{Me}_{x} \mathrm{O}_{y}$. Где $\mathrm{Me}_{x} \mathrm{O}_{y}=\mathrm{ZnO}, \mathrm{CdO}, \mathrm{SnO}, \mathrm{CuO}, \mathrm{Fe}_{2} \mathrm{O}_{3} ; m$ равно 2 или 10 mass.\%. Измерена микротвердость композитов и стеклянной подложки, на основании которых рассчитана микротвердость покрытий. Установлены зависимости между микротвердостью покрытий, их показателем преломления и плотностью упаковки частиц дисперсной фазы золя в слой покрытия.

DOI: $10.21883 /$ JTF.2017.01.44023.1842

Оксидные покрытия, наносимые на поверхность стекла методом золь-гель технологии, сводящимся к нанесению на стеклянную подложку пленкообразующего раствора, используются для изменения оптических, механических и других свойств стекла, расширяя тем самым область его применения [1-3]. При этом значительное влияние на свойства стеклянных композитов оказывает не только оксидный состав пленок, но и вид прекурсоров, используемых для приготовления пленкообразующих растворов - золей [4].

Целью настоящей работы является установление зависимости микротвердости покрытий от плотности упаковки частиц дисперсной фазы золя в слой, показателя преломления покрытий и вида прекурсоров, используемых для приготовления золей.

\section{Изготовление композитов}

Двухсторонние покрытия наносили окунанием в пленкообразующие растворы (золи) образцов флоат-стекла размером $50 \times 50$ и толщиной $4 \mathrm{~mm}$ марки М1 по ГОСТ 111-2001, вырезанных из одного листа форматом $3 \times 6 \mathrm{~m}$. В образцах различали 2 стороны, условно названные „оловянная“ и „газовая“. Наличие их предопределяется технологией производства листового термически полированного стекла, когда при выработке ленты одна ее сторона соприкасается с расплавом олова, a противоположная контактирует с защитной газовой атмосферой флоат-ванны.

Скорость извлечения подложки из растворов сохранялась в конкретном цикле нанесения строго постоянной и для разных образцов изменялась от 3.8 до 5.8 и $17.3 \mathrm{~mm} / \mathrm{s}$. После окунания образцы выдерживали на воздухе в течение $1-1.5 \mathrm{~h}$ для завершения процессов гидролиза и поликонденсации, испарения растворителя и подсушивания покрытия, после чего их помещали на $30 \mathrm{~min}$ в микроволновую печь для окончательного закрепления пленки.
Исходные материалы для приготовления золей: источник $\mathrm{TiO}_{2}$ - гидролизующееся соединение тетраэтоксититан $\mathrm{Ti}\left(\mathrm{OC}_{2} \mathrm{H}_{5}\right)_{4}$, модифицировали золи оксидами $\mathrm{ZnO}$, $\mathrm{CuO}, \mathrm{CdO}, \mathrm{SnO}, \mathrm{Fe}_{2} \mathrm{O}_{3}$ квалификаций ЧДА или ХЧ, вводимыми в золи в количестве 2 или 10 mass.\%. Перечисленные оксиды предварительно растворяли в соляной или азотной кислотах квалификации ЧДА, гидролиз кислый, катализатор гидролиза - соляная или азотная кислота ЧДА по ГОСТ 3118-77. Растворитель - изопропиловый спирт по ГОСТ 9805-84

Суммарное массовое содержание оксидов $\mathrm{TiO}_{2}+$ модифицирующий оксид в растворах (алкозолях) сохранялось равным 5 mass.\%. Длительность созревания золей изменялась от 2 до 20 days, растворы хранились при комнатной температуре.

\section{Контроль золей и композитов}

Пропускание золями света в слое толщиной $20 \mathrm{~mm}$ на длинах волн $315,364,400,540$ и $670 \mathrm{~nm}$ измерялось фотокалориметром КФК-3. В предположении, что форма частиц сферическая, размер дисперсной фазы $r$ рассчитывали по уравнению Геллера [5], исходя из измеренного пропускания золями оптического излучения. Учитывая ограниченность метода, позволяющего производить расчеты только для „белых“ золей, для окрашенных медь- и железосодержащих растворов выбирались длины волн, на которых поглощение комплексов меди и железа минимально.

Эмпирическое уравнение Геллера [5] применяется для определения размера коллоидных частиц, если их размер лежит в пределах от 1/10 до 1/3 длины волны падающего оптического излучения, в виде

$$
D=k \lambda^{-a},
$$

где $D-$ оптическая плотность золя, $k-$ константа, не зависящая от длины волны, $\lambda$ - длина волны, $a-$ 
Взаимосвязь коэффициентов $a$ и $Z$ в уравнении Геллера

\begin{tabular}{c|c|c|c|c|c}
\hline$a$ & $Z$ & $a$ & $Z$ & $a$ & $Z$ \\
\hline 3.812 & 2.0 & 3.121 & 4.5 & 2.457 & 7.0 \\
3.868 & 2.5 & 3.060 & 5.0 & 2.379 & 7.5 \\
3.573 & 3.0 & 2.807 & 5.5 & 2.329 & 8.0 \\
3.436 & 3.5 & 2.659 & 6.0 & - & - \\
3.284 & 4.0 & 2.533 & 6.5 & - & -
\end{tabular}

показатель степени, зависящий от соотношения между размером коллоидной частицы и длиной волны падающего света, и характеризуется параметром $Z$, равным

$$
Z=8 r \pi / \lambda \text {. }
$$

Оптическая плотность золей на различных длинах волн измерялась экспериментально и по результатам строился график в координатах: $\lg D=f(\lg \lambda)$. Значение $a$ определяется как тангенс угла наклона полученной прямой. Значение $Z$ определяется по таблице, радиус частицы - по выражению (2).

Плотность упаковки частиц дисперсной фазы $\gamma$ в слой наноразмерного покрытия рассчитывали без учета взаимодействия между частицами, как и в [6], по выражению (3)

$$
\gamma=0.75 \cdot 2 r \cdot \varphi,
$$

где $\varphi$ - объемная доля дисперсной фазы золя, \%.

Следует отметить, что размер частицы дисперсной фазы в золе тем больше, чем больше размер частицы в высушенном и термообработанном покрытии, однако можно предположить, что результаты расчетов $\gamma$ по размеру дисперсной фазы золя будут пропорциональны плотности упаковки, существующей в покрытии. Кроме того, скорость нанесения, определяющая режим течения золя относительно стеклянной подложки, также существенно влияет на упаковку частиц в слой, потому необходимо сравнивать свойства покрытий, полученных при одинаковой фиксированной скорости нанесения.

Толщину $h$ и показатель преломления $n$ пленки измеряли методом спектральной эллипсометрии на приборе Uvisel 2 фирмы HORIBA. Микротвердость композитов $\mathrm{H}_{3}$ измеряли твердомером Nexus 4504-IMP, нагрузка $100 \mathrm{~g}$, длительность нагружения $10 \mathrm{~s}$. По результатам измерений в соответствии с $[7,8]$ рассчитывалась микротвердость покрытий $H_{1}$ по выражению (4)

$$
H_{1}=\frac{H_{3}-(1-b) H_{2}}{b},
$$

где $H_{1}, H_{3}, H_{2}$ - соответственно микротвердости покрытия, композита и стеклянной подложки.

Значение величины $b$, названной автором $[7,8]$ долей твердости покрытия в твердости композиции и входящей в формулу (4), рассчитывалось по выражению (5)

$$
b=1-\frac{(0.14 d-h)^{2}}{0.0196 d^{2}},
$$

где $h$ - толщина покрытия, $d-$ диагональ отпечатка индентора.

\section{Обсуждение результатов}

В настоящей работе была измерена микротвердость всех изготовленных образцов. Графики зависимости микротвердости покрытия от плотности упаковки частиц дисперсной фазы в слой приведены на рис. 1, $a$. Каждая из прямых характеризует изменение микротвердости покрытия, полученного при фиксированной скорости нанесения. Линейные зависимости $H_{1}=f(\gamma)$ описываются величинами достоверности аппроксимации, равными 0.88 и 0.75 для скоростей нанесения соответственно 3.8 и $5.8 \mathrm{~mm} / \mathrm{s}$. Для скорости нанесения $17.3 \mathrm{~mm} / \mathrm{s}$ установить такую зависимость не удалось, вероятно, из-за недостаточного количества экспериментальных данных.

Из графиков рис. 1, $a$ следует, что микротвердость покрытий растет с увеличением плотности упаковки частиц золя в слой. Следует отметить, что при плотности упаковки более $40 \%$ скорость нанесения $5.8 \mathrm{~mm} / \mathrm{s}$ является оптимальной, и соответствующие образцы обнаруживают максимально высокую микротвердость. При плотности упаковки менее $40 \%$ разница в микротвердости покрытий, полученных при скоростях нанесения 3.8 и $5.8 \mathrm{~mm} / \mathrm{s}$, находится в пределах погрешности опытов.

Рис. $1, b$ подтверждает предположение об оптимальном значении скорости нанесения, равной $5.8 \mathrm{~mm} / \mathrm{s}$, для плотности упаковки частиц в слой. При этой скорости показатель преломления покрытий наибольший. В соот-
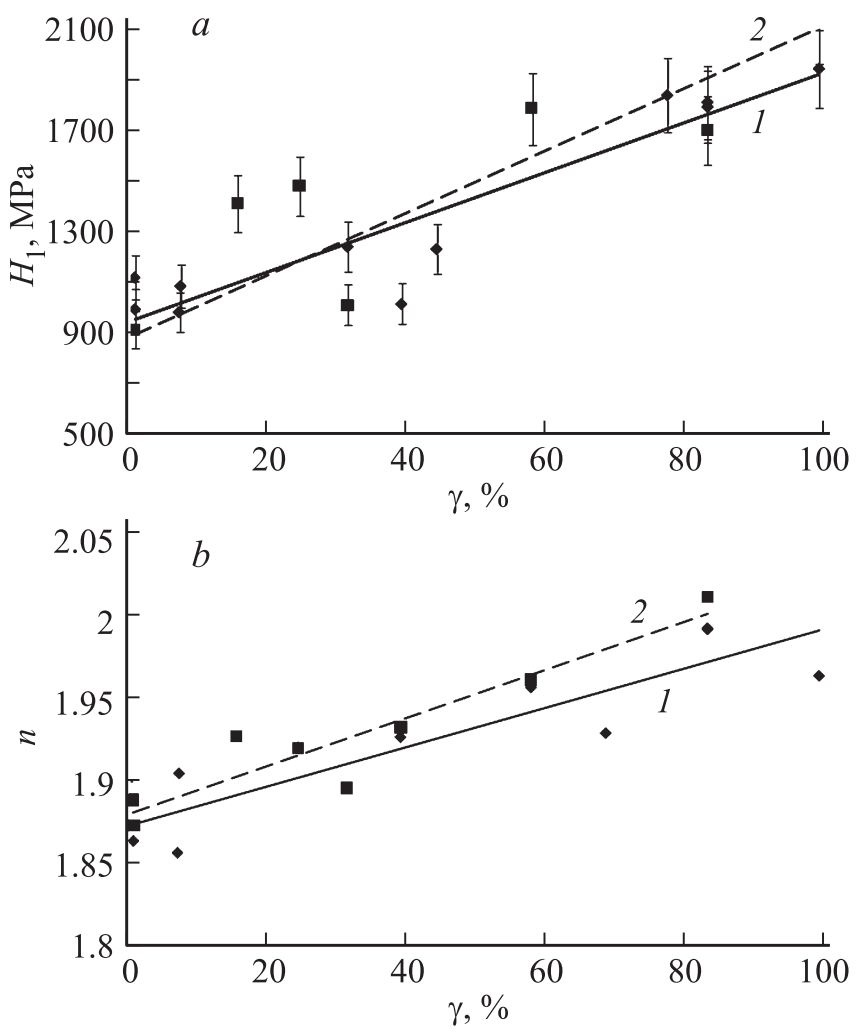

Рис. 1. Графики зависимости микротвердости $H_{1}(a)$ и показателя преломления $n(b)$ покрытий от плотности упаковки частиц $\gamma$ дисперсной фазы в слой. Скорость нанесения: $1-3.8,2-5.8 \mathrm{~mm} / \mathrm{s}$. 


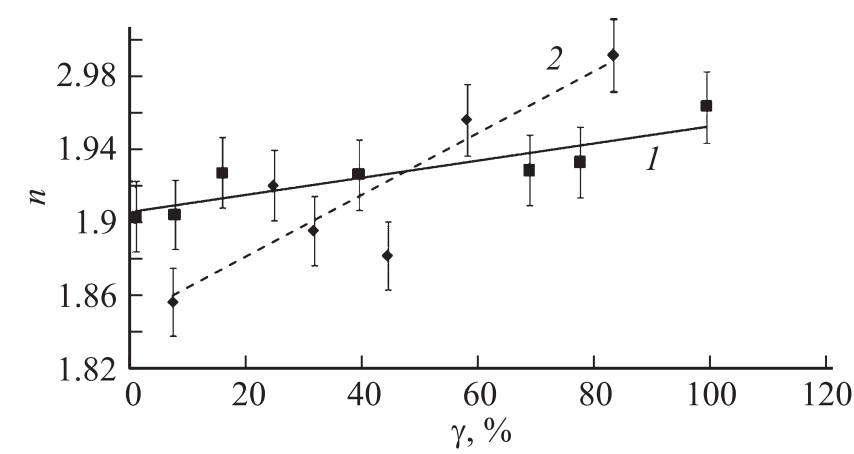

Рис. 2. Графики зависимости показателя преломления $n$ покрытий от плотности упаковки частиц $\gamma$ дисперсной фазы в слой. Скорость нанесения $3.8 \mathrm{~mm} / \mathrm{s}$. Прекурсоры: 1 - азотная кислота и нитраты, 2 - соляная кислота и хлориды.

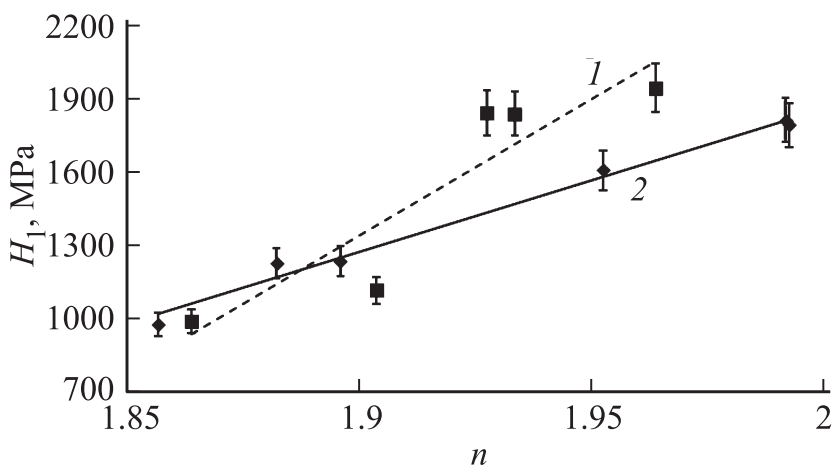

Рис. 3. Графики, связывающие показатель преломления $n$ и микротвердость покрытий $H_{1}$. Прекурсоры: 1 - азотная кислота и нитраты, 2 - соляная кислота и хлориды. Скорость нанесения $3.8 \mathrm{~mm} / \mathrm{s}$.

ветствии с [9] показатель преломления пористого тела, какими являются золь-гель покрытия, в существенной степени зависит от их пористости и состава газов, заполняющих поры.

Последний вывод хорошо иллюстрируется графиками на рис. 2. Известно, что показатель преломления хлороводорода и соляной кислоты ниже, чем азотной кислоты [10]. Возможно, это является одной из причин более высокого показателя преломления покрытий, полученных из нитратсодержащих прекурсоров в области малых плотностей упаковки частиц (менее 40\%), т.е. в области достаточно высокой пористости покрытий. При дальнейшем повышении плотности упаковки (до 40\% и более) пленки, полученные нитратным синтезом, имеют меньшее значение показателя преломления, что может объясняться их меньшей толщиной (по результатам наших измерений у покрытий, полученных нитратным синтезом, толщина примерно в $1.2-1.4$ раза меньше) и интенсивным проникновением низкопреломляющих оксидов натрия и кремния из стеклянной подложки [11]. Линии трендов, описывающие линейные зависимости показателя преломления от плотности упаковки частиц, характеризуются величинами достоверности аппроксимации 0.79 и 0.84 для покрытий из нитрат- и хлоридсодержащих прекурсоров соответственно.

Микротвердость покрытий менее чувствительна к природе прекурсора, незначительное отличие наблюдается в области значений $\gamma$ менее 50\% - здесь микротвердость покрытий из хлоридсодержащих прекурсоров несколько ниже. Соответствующие линейные зависимости описываются величинами достоверности аппроксимации 0.84-0.97.

Поскольку и показатель преломления, и микротвердость покрытий повышаются с ростом плотности упаковки частиц в слой, закономерно предположить, что эти свойства покрытий будут взаимосвязаны.

Действительно, микротвердость покрытий повышается с ростом их показателя преломления, соответствующие линейные зависимости описываются величинами достоверности аппроксимации $0.76,0.84$ и 0.60 соответственно при скоростях нанесения $3.8,5.8$ и $17.3 \mathrm{~mm} / \mathrm{s}$. По сравнению со скоростью нанесения $3.8 \mathrm{~mm} / \mathrm{s}$, при скорости $17.3 \mathrm{~mm} / \mathrm{s}$ значения показателя преломления и микротвердости покрытий понижаются.

На рис. 3 величина микротвердости повышается по мере роста показателя преломления покрытий для нитрат- и хлоридсодержащих прекурсоров. Графики линейных зависимостей описываются величинами достоверности аппроксимации 0.78 и 0.84 (нитрат- и хлоридсодержащие прекурсоры соответственно). Обе линии на рис. 3 пересекаются в точке с координатами 1.91 и $1300 \mathrm{MPa}$. Это подтверждает предположение о том, что на формирование микротвердости и показателя преломления покрытий влияет не только плотность упаковки частиц дисперсной фазы золя в слой. Если показатель преломления зависит как минимум от плотности упаковки частиц в слой, пористости покрытия, природы заполняющих поры газов и диффузионных явлений компонентов из стеклянной подложки в покрытие, то механизм формирования микротвердости покрытий, полученных из золей, пока недостаточно ясен и требует дальнейших исследований.

\section{Заключение}

По результатам исследований могут быть сделаны следующие выводы:

плотность упаковки частиц дисперсной фазы золя в слой покрытия зависит от их размера, объемной доли и скорости течения золя относительно подложки скорости нанесения покрытия;

показатель преломления и микротвердость покрытий увеличивается по мере повышения плотности упаковки.

В рамках настоящей работы скорость нанесения, равная $5.8 \mathrm{~mm} / \mathrm{s}$, является оптимальной с точки зрения положительного влияния на величину микротвердости и показателя преломления покрытия. 
Прекурсоры, использованные для приготовления золей, оказывают существенное влияние на показатель преломления покрытий. Микротвердость менее чувствительна к виду прекурсоров.

Работа выполнена при частичной финансовой поддержке базовой части госзадания Министерства образования и науки РФ, в том числе проект 2284, и гранта РФФИ, проект № 14-43-08049.

\section{Список литературы}

[1] Справочник технолога-оптика / Под ред. М.А. Окатова. СПб.: Политехника, 2004. 679 с.

[2] Пруненко Е.К. // Оптич. журн. 2010. Т. 77. Вып. 4. C. 80-84.

[3] Каманина Н.В., Богданов К.Ю., Васильев П.Я., Студенов В.И. // Оптич. журн. 2010. Т. 77. Вып. 2. С. 84-86.

[4] Аткарская А.Б., Шеманин В.Г. // ЖТФ. 2015. Т. 85. Вып. 7. C. $107-111$.

[5] Слепнева Л.М., Горбунова В.А., Слепнев Г.Е. // Наука и техника. Бел. нац. техн. универ. 2014. № 6. С. 55-59.

[6] Аткарская А.Б., Евтушенко Е.И., Нариев В.М., Привалов В.Е., Фотиади А.Э., Шеманин В.Г. // Научнотехнические ведомости СПбГПУ. Физико-математические науки. 2015. № 1(213). С. 136-144.

[7] Быков Ю.А. // Металлургия машиностроения. 2011. № 1. C. 9-19.

[8] Быков Ю.А. // Металлургия машиностроения. 2011. № 2. C. $27-36$.

[9] Черемской П.Г., Слезов В.В., Бетехтин В.И. Поры в твердом теле. М.: Энергоатомиздат, 1990. 375 с.

[10] Рабинович В.Я., Хавин 3.Я. Краткий химический справочник. Л.: Химия, 1978. 392 с.

[11] Аткарская А.Б. // Стекло и керамика. 1998. № 5. С. 9-11. 